\title{
5 Challenges and dilemmas of integrating gender in the field of environment and development at SEI
}

\section{Metrics and metaphors}

\author{
By Andreea R. Torre \\ In conversation with Natalia Biskupska, \\ Maria Escobar, Laura Forni, Emily Ghosh, \\ Ha Nguyen, and Lisa Segnestam
}

The growing relevance associated with gender equality in international policymaking, including in the Sustainable Development Goals, the Sendai Framework for Disaster Risk Reduction, and the Paris Agreement on Climate Change, has raised new demands for gender expertise in areas where engagements with gender experts had been few. As a result, and following donors' interest in gender mainstreaming, the involvement of gender researchers is becoming more common in projects and programs ranging from water and sanitation, climate change, disaster risk reduction among many others.

Yet, although gender has been recognised within environmental research and policy, and conceptualisations about gender and environment have also dynamically evolved since the late 1970s and 1980s (Arora-Jonsson, 2017; MacGregor, 2017), the actual integration of gender perspectives and analysis within research and sustainability projects is still a challenge. Lack of awareness or technical 'know-how' are among the reasons for this inertia. As some of us in this chapter mention, more conventional environmental research had often directed its focus towards environmental sustainability, for instance, or inequalities on a larger scale (e.g. urban spaces with fewer resources) neglecting the relevance of understanding smaller scale experiences and relationships.

The increasingly common focus on addressing climate change impacts in both research and programming for development, adds further layers to the positioning of gender experts within the broader spectrum of social researchers and technical specialists called upon to help ensure that the ecological and social unsustainability of current development paths is addressed and that equitable strategies are proposed to redress this trajectory. In this case gender professionals have to engage with a common (neoliberal) framing of environmental issues as primarily an aspect of natural science, or techno-scientific problems often calling for technical solutions (e.g. engineering of shock-resistant crops), market-based mechanisms and regulatory interventions (e.g. emission trading) and the intrusion of non-state actors (e.g. corporations) to mitigate or to adapt to environmental hazards and climate change impacts. 
This chapter develops through a conversation with fellow gender specialists and researchers who have placed gender at the centre of their environmentrelated studies and policy engagement in the different centres of the Stockholm Environment Institute (SEI) across Asia, Europe and the USA. Marisa Escobar, Andreea R. Torre, Laura Forni, Lisa Segnestam, Ha Nguyen and Emily Ghosh reflect on the challenges of assiduously working for bringing gender in, and keeping it central, to the realms of environmental science, capacity-building activities and policy engagement.

Those challenges are multiple and take place at different scales. They relate to complexities of situated geo-political identities of 'being a woman scientist' and to differing disciplinary and professional backgrounds as well as to the nature of work that involves navigating encounters between epistemologically masculine fields which often overlook the micro-scale of human and more specifically women's experiences. The reflections in this chapter are hence rooted in the never-ending dilemmas about self-identifying and being identified as gender professionals, the ontological and epistemological tensions between natural and social science researchers, as well as the politics and practice of gender work in a historically technical, and increasingly managerialist field.

\section{Self-identifying and being identified as gender experts}

Reflexivity and identity positioning are processes that allow researchers to connect to their work experiences and grasp the intricate relationships, intrinsic tensions, and winding paths of learning that often shape such experiences. Calls for thorough analysis of the working experiences of gender experts in different research fields and institutional contexts are not new, and responses have developed especially in the field of international development (Prügl, 2013; Ferguson, 2015; Bustelo, Ferguson \& Forest, 2016). In keeping with this ongoing work, a self-reflexive exercise focusing on our experiences and shifting, troubled identities as gender professionals in the specific field of environment and development kicked off our conversation while connecting through cyberspace in the Skype chatroom.

We reflected on the 'roads' to our current positions within SEI and on what it takes to be identified as gender specialists. Kunz and Prügl (2019, p. 3) highlight how gender experts, while defining a new body of knowledge and marketing their ideas in multiple spaces, have also established a new profession. They 'implement gender mainstreaming, offer specialised training, spread gender-equality considerations throughout organisational structures and seek to bring about social change through the implementation of gender-sensitive projects'. What has strongly emerged from our conversations is the diversity of experience, of understandings about being a woman scientist and gender specialist.

In our roles as SEI researchers, some of us feel caught between the conflicting positions of the 'gender specialist' expected to provide technical advisory services and the feminist researcher, who is concerned with transforming the workings of unequal power. Others reflected on their evolving position from technical 
scientist to 'gender champions' in their technical fields of water and energy, or on their early steps towards a future, aspired profession. Finally, we observed how power dynamics and intersecting social variables of place, class, ethnicity, race infuse a political twist to our work on gender and environment in development contexts. The variety of SEI office locations, our areas of expertise, academic and professional paths, allowed for insightful stories to be told.

Andreea: How would you define gender professionals and do you consider yourself one of them?

Lisa: I have a background in economic history with a focus on intersectionality and vulnerability to climate change. Now I can consider myself a gender professional since I've spent my last 10 to15 years working on these issues although I'm not a gender professional by training. It's more about putting together different pieces of theory and practice.

Marisa: I don't consider myself as a gender professional, but I think that through my involvement with the Gender and Social Equity program [GSE] at SEI, I've been a bit of a champion on gender issues wherever I go. I have been involved in incorporating gender in modelling work through the GSE program and in the 'Water Evaluation and Planning' [WEAP] tools. In workshops where I go, even if many are conscious about these issues, I think someone needs to talk about them. Someone needs to bring those issues to the table. To say, for example, hey, this is not a balanced workshop, because it is not $50 / 50$. So, I think I bring that voice with more arguments to make sure that people are aware.

Andreea: Few years ago, I wouldn't have considered myself a gender specialist; most probably because of my background which is not strictly in gender studies. I got closer to the gender and development field though the work that I have done. The gender specialist identity has emerged and was shaped through my first academic position and through engagement with feminist organisations and development agencies working on women's issues in the South Pacific. Yet at that time I would identify myself and I was identified by others as a sociologist and lecturer and researcher in development. Now, by being part of the Gender, Environment and Development cluster at SEI, this identity [gender specialist] has become more solidified. Personally, I'm interested in understanding that messiness of the world around us, and where gender comes into it rather than just focussing on gender as such. I'm interested in all those dynamics and how they come into place. So maybe, technically I may be defined as a gender professional, but I feel that I am more than that.

Ha: I have a background in gender and development studies and I previously worked as a gender focal point providing support to various projects on agriculture and rural livelihoods. For me gender professionals are those who make a living by offering services and advice on gender. So, in that sense I consider myself as a gender professional. I did not consider myself a gender professional in my previous work - although I was trained in gender - just because of the nature of the projects I was working on and which did not have 
much of a focus on gender. I do consider myself a gender professional now as I work on projects on gender and I do consultancies on gender. This has become my focus.

Natalia: I would have described the gender specialist as a standalone person who works on gender. Whatever that means I wouldn't know - a person working on those issues. But now that I'm involved in this area, I've realised that gender professionals are people working in certain sectors on the same issues as others but explaining things in a unique way and looking at gender aspects of those issues. So rather than being a standalone person, I see them as integrated in those sectors. The effectiveness of that work is the challenge; trying to bring down barriers and being heard in those sectors. I think I'm a want-to-be gender professional but still have a lot to learn.

Emily: Through my involvement in the Gender and Social Equality program, I am currently working on research related to gender issues in the energy sector. I would not consider myself a gender professional at this time as this area of research is still new to me. I see a gender professional in our field as someone with knowledge of the history and issues related to gender within various aspects of sustainability and development and with a focus on gender in a large portion of their research. I think of myself more as a gender champion within the workplace, pushing for more awareness on gender issues and gender inclusion in the projects we do.

Laura: I don't consider myself a gender expert in the wider scheme of things. I'm a technical scientist with a background in economics and have worked on water resource management. Through the GSE program I started exploring gender in the modelling work considering the mobility aspects in relation to gathering water and other projects where funders have asked for gender components to be included. Hence, I do consider that I became a water-based gender professional or a professional at the intersection of gender and water resource management. This is because of all the reading and work that I have done in the last two years. Moreover, as the chair of the gender and diversity committee in the SEI US, I helped developing policies for the institute regarding equity, diversity, gender and inclusion. And I think that because of the engagement within this process I became a lot more aware of gender in the workforce. As we explore the inequalities in our scientific work, it is inevitable to become aware of the inequalities outside the science. Such is for example the role of, or the lack of, women in decision making and scientific panels. As well as of the biases that are presented in the societies we are located in or we work with internationally.

Rather than voicing merely personal narratives, the relevance of this discussion is to be found in the ways it allowed us to approach connections: between the personal, the social, and the political as well as the linking with the 'historic situation', 'social structures', and 'moment of experience' (Denzin, 1997: 39) which shape career paths and professional identifications. 'There is a clear argument for intersectionality emerging within the group', as Lisa observes anticipating 
matters that will be picked upon later in this chapter. The emerging narratives tell a story of a process of 'getting into the work' of the gender professional. It is about gradually growing into an identity as a researcher, a scholar, a professional, and a champion of gender equality in the environmental field.

It also tells us that what makes a gender expert is an assemblage of instruments (theory, background, mainstreaming skills etc.) making up, at various degrees, a 'toolkit' of expertise. This is a dynamic process. This is a process of becoming those different identities and concomitantly of overcoming the often-encountered epistemic injustices (Fricker, 2007) of being women scientists and/or of engaging and bringing in the gender analysis in technical fields.

Conversations below unpack on one hand the positioning of women technical scientists and on the other, that of gender specialists in the natural resource management fields and environmental organisations. While Laura, Emily and Marisa stress the trivial visibility that women scientists are given because of their gender identity, Ha's reflection pushes the discussion farther to uncover the lack of legitimacy gender studies/analysis suffer as a science and as a discipline against the epistemic authority of technical sciences. Yet in both cases, as Natalia pointed out earlier, rather than shaping a stand-alone profession, we work towards integrating our work and understanding in various, diverse sectors of environment and natural resource management. And in both cases, there are barriers to overtake and knowledge to establish.

\section{Technical women in technical fields: the everlasting struggle for epistemic credibility}

In her analysis of forms of epistemic injustice, Miranda Fricker (2007) defines the experience of being devalued as a knower as 'testimonial injustice'. She notes how individuals can face a lack of epistemic credibility because of a collectively shared identity preconception. In these circumstances a woman can be denied recognition. She can be marginalised as a knower because of a systemic prejudice regarding her gender. Such is the condition of being a woman scientist in a technical field constructed as 'masculine' through consolidated norms and practices of knowledge production.

The rise of modern science in Western Europe has been associated with dynamics of professionalisation of science and its exclusion from the personal/domestic realm - a locus for the production of science in earlier times (Abir-Am \& Outram, 1987). This shift encouraged the collective identification of men with the external, the public, the rational world while ascribing women to the emotional dimension of their nurturing roles and 'soft' skills. A gender binary was established to support assumptions about a 'structured incompatibility of women and science - and between women and scientific rationality' (Seager, 2017: 38). Commenting on the state of science, as well as environmental politics, in the late twentieth century, Merchant $(1980,2006)$ points to the persistent belief in 'objectivity' and decontextualised knowledge among Western scientific communities. A belief that is responsible for the limited questioning of grand narratives underpinning the 
testimonial injustice which still prevents women scientists from fully engaging in the epistemic practices of science.

Laura, Emily and Marisa dialogue here around the troubles and injustice women scientists must overcome in technical settings. They recall accounts of their own experiences and of other women colleagues not being fully accepted as scientists in a field which is epistemologically masculine. They observe how women are either unwelcome or, when in, they are 'invisible' knowers and expected to perform stereotypically 'domestic' and 'feminine' tasks. When that assumed 'performativity' is not exercised by women professionals, 'accommodating gender in a project turns somewhat uncomfortable' - as Marisa's words brilliantly point out at the end of this exchange.

Marisa: In many instances of my professional work I have faced the all too common reality of being the only woman in the classroom or in project meetings. As such, I had to overcome some of the cultural biases that prevent women to occupy these roles. Such biases come in many subtle forms and on a daily basis. I encounter mansplaining, or associated forms of it, quite often. These events of either interrupting my explanations, giving me unsolicited advice or ignoring my opinion, disturb the regular flow of a workday, keeping me down and requiring time to recover. This happens at meetings where my voice or ideas seem to not be heard.

In other occasions, what happens is that my emails are not read or are ignored, requiring me to go through a male colleague to produce the e-mail I need the counterparts to read. By doing this I get my work done, but of course it requires more work and frustration. Difficulties may arise when participating in management meetings. In those cases, there is a level of assumed knowledge and a level of comfort from, mostly male, colleagues in higher ranks that is counterproductive for an effective transition into increasing levels of seniority.

Laura: Not long ago, I attended a workshop where capable female professionals, including myself, participated. One of the male presenters made a joke about bringing water pumps to low income communities and the potential of making women fatter because they wouldn't have to walk to collect water anymore. In spite of the distasteful comment, several laughed. Only a few perceived the joke as offensive and only admitted it later when I brought it up. My impression was that, overall, it was acceptable. It was 'just a joke'. In a culture that is so immersed in the 'man's way of thinking' it is hard to create a safe space for women to feel valued.

Emily: Yes, unfortunately, more often than not, a woman will be asked to do the admin tasks in a project 'because they are good at it' and because this at least gives them an opportunity to work on a project in some form. However, this affects future opportunities to engage in technical work. There needs to be greater emphasis on giving women a seat at the table in decision-making processes. By doing so, not only a diverse set of perspectives is included, but this can help recognise and avoid having gender-unequal roles in a project. 
However, greater gender inclusion in a project does not always guarantee gender inclusive outcomes. For example, society deeply undervalues the contributions of household work, such as cooking and cleaning, in an economy; work that is predominantly done by women in every country in the world. As a result, energy policy decisions may be skewed to prioritise industrial energy demands (i.e. male-dominated fields) rather than ensuring, for instance, safe and reliable electricity supply to households. This is why advocating for gender analysis in projects, alongside the typical environmental, social and economic analyses, is paramount.

Marisa: Not all projects require gender integration and when this is not explicit in the projects, there is an additional challenge in order to motivate gender considerations with the funders and project team. This challenge is twofold: first, why add a gender layer to a water analysis project that is already complicated in itself; and second, the women team-members often play, or are expected to, an administrative support role.

This second point is important because when gender considerations are brought to the surface as part of the project, it generates an uncomfortable situation where the role of the woman needs to be shifted from administrative support to technical expert. This situation potentially leaves the men in the team without the appropriate administrative support and perhaps with the burden of sharing some of that work. At this point, accommodating gender in a project turns somewhat uncomfortable and with the potential to harm the politics of managing the project.

\section{Gender analysis: sitting on the margins}

Having walked a different path, that of the researcher and gender specialist in an environmental organisation like SEI, Ha adds her views to the discussion above. They highlight the knowledge politics encouraging forms of epistemic authority of the technical sciences and engendering spaces where gender analysis lacks recognition and legitimacy. In those spaces, where paradigms of scientific objectivity are dominant, problems are seen as mainly technical and hence in need of technical solutions that natural sciences only appear to be able to provide.

Furthermore, the widely spread essentialist association of gender studies with 'women issues' has further contributed to relegating gender analysis to the epistemic margins of environmental research and policy. Gender is deemed peripheral, if not irrelevant, to the technical efforts to correct environmental damage and efficiently manage natural resources, as Ha narrates below. Gender specialists are expected to show up armed with tools (e.g. techniques and measurement instruments) to 'fix' rather than transform unequal and unjust power relations which should be at the heart of the gender agenda (Cornwall, 2007).

Ha: It's a 'half-way commitment'. In my previous position as gender adviser, efforts were made to set up an organisational structure that aimed to support 
gender mainstreaming. This structure included assigning a gender lead, setting up a gender working group, conducting gender scoping in the organisation, developing gender mainstreaming policy and minimum standards. These were often demonstrated as the organisational commitment to gender equality, but they were lifeless. No further efforts were made to ensure that the policy and guidelines were followed. No one was held accountable for not following the policy, responding to gender advices, nor delivering expected results regarding gender.

'It's something to show off': It was not challenging to request budget for gender analysis, disaggregated beneficiaries or capacity building for women as long as those activities did not affect what the programs were set out to do. After all, having gender budget was something to show off. I encountered huge resistance (e.g. excuses, disengagement...) once gender power relations were introduced and commitment to gender equality implied or required changes in program design, approach or implementation process. I think many program folks preferred to conceptualise gender as sexual dichotomy where they could disassociate themselves from the development context, rather than power asymmetry where they might well be part of the (gender inequality) problem.

'I am a dog without teeth': This is a phrase that one of my gender specialist colleagues called herself. I felt exactly the same. As the gender lead, I was requested to review program proposals and strategies, but nobody was held accountable for responding to our recommendations to strengthen the gender dimensions. It was no more than ticking the box.

\section{Overcoming the 'troubles' (1): the gender expert}

Ha tells us about her work with Geographic Information Systems (GIS) experts and explains how the troubles related with integrating gender are caused by the lack of awareness of the importance of gender issues in their project, and how it is marginalised as a field of expertise. There would be more receptivity if there was consensus around social justice as the main purpose of this exercise. One way to integrate gender, Ha highlights, is for ourselves - technical and social specialists, planners - to critically engage and reflect on our own positioning (as development professionals, researchers, technical scientists etc.) within the very game of power relations.

Ha: I was tasked to support a climate forecasting service developed by GIS experts and technicians to reach out and benefit women and men farmers in a southern province of Vietnam. We had conducted a gender assessment to point out problems faced by some groups of farmers, particularly ethnic minority women and their communities, in accessing climate services and using climate forecasts in livelihood planning. The heart of the problem was the centralised power of the state that determines access to and use of different types of climate information, directs agriculture planning and regulated 
water resource allocation aligned with economic growth objectives. As a result, they did not target small-holder ethnic minorities, women and their livelihoods because these did not fall under those objectives. These groups could not use these services to adapt their livelihoods to climate change.

What else does this experience also tell us? One: there was an assumption that once you hire a gender specialist 'to do gender', gender issues will be addressed but not at the expense of altering the entire 'technical exercise'. Two: in technical areas of expertise such as GIS, gender is not considered a science. Resources are mostly committed to technical interventions rather than addressing power-related inequalities and social justice.

Andreea: So, what I'm hearing here is that doing work on gender is an instrument for bringing in change by transforming power relations. Am I right?

$H a$ : We need to change our perception and ways of addressing gender and social inequality. We have to recognise that we are part of the problem and also the solution. For example, back to the case that I mentioned earlier, if the GIS program team does not change the way they design and deliver the forecasting tool and service, they will serve the existing structure that produces unequal access to climate information and undermines coping strategies of the traditionally marginalised grassroots groups. Being aware of our role in producing inequality might create the urge to engage with and address it.

\section{Overcoming the 'troubles' (2): the technical scientists}

While Ha's proposal of overcoming troubles connects firmly with her background and current positioning as gender specialist, other proposals take different forms. Emily and Laura provide a detailed account as technical scientists engaged in integrating gender in projects. They see the relevance of sharing knowledge on gender with their peers at the outset of project work, as well as of engendering a change in methodology which focuses on the individual and her place at the centre of contextual dynamics and relations of power.

Andreea: How are our experiences of integrating gender into our work on environment different based on your areas of work at SEI?

Emily: In the energy sector, we are generally finding that more project terms of references' specifically request that a gender analysis be conducted as part of the project. We often review the health, social and economic impacts of the various climate mitigation measures that are analysed in a project. But additionally, we are now asked, what are the gender implications of that? Hopefully in the future, GSE concerns will no longer be an afterthought, but an integral part of energy and climate mitigation policies.

Andreea: Can you say a little bit more on that? How do you actually do it?

Emily: Well, there's been a lot of discussion in the last year on how to analyse the gender impacts of different climate and energy policies. Energy planners are often unaware of the gender implications of their decisions. So, what I have been working on recently is to put together a detailed overview of gender 
issues in the different aspects of energy planning and create a training module for LEAP for energy planners to learn about gender issues through training exercises. Depending on the project, this module is something that could be referenced when doing a study of various policy options.

Major gender and energy issues in rural areas of developing countries revolve around the type of energy consumed within a household, and how that affects women who predominately do household work. When we are looking at household energy demand, there's a list of concerns related to gender that need to be considered related to time burdens, pollutant exposure, and various health and safety concerns. On the energy supply side, there are concerns related to displacement, for example from hydropower dams, or pollution from coal plants, and how that can potentially disproportionately affect women.

We looked at those issues in one project in Jamaica which specifically asked for a gender analysis. In this project, we identified a number of climate mitigation options for the country and then analysed the gender impacts from a health perspective, a safety perspective, as well as on general productivity and lifestyle. While this was more of a qualitative analysis, we are now also developing methods to quantify the impacts so that our energy planners can say: 'Okay, this is the time lost for a person that is spending 10 hours a week collecting fuelwood instead of using LPG or electricity for cooking - time that could be used for income-generating activities or school.' We would like to help energy planners quantify those impacts and put numbers to the decisions that are made. Yet, sometimes the data available for quantifying gender impacts is limited.

Andreea: Do you feel that there is greater demand for quantitative data rather than, as you say, more qualitative understanding of the issues?

Emily: I think that there is room for both. Looking at impacts from a quantitative perspective can be useful, especially for technical energy planners who look at numbers to understand the scale of a problem. But qualitative analysis also has a place in the energy sector.

Laura: I see the value of quantitively addressing gender issues, although, in these cases, the gender analysis often gets stuck in counting people. I believe we need to go beyond that, for example in addressing the impacts of water distribution and how they differ by gender. One example is looking at the 'opportunity' cost of women's labour in collecting water when they don't have access to water in their premises. So that gives a quantitative sense of one of the impacts of unequal access to water and the social pressure put on women to collect water elsewhere when there is no access to it at home.

Also, in terms of achieving equality, I think empowerment is key. I see the value of showing gender differences in the numbers to inform policies, but also to create the awareness around gender aspects that need to be considered when we examine how water is managed within a watershed. We need more tools though to continue addressing the relevant linkages between gender differences in water management impacts, not just technical tools but also 
qualitative tools that can help us understand and identify the main aspects the model needs to focus on.

\section{A change in methodology}

With a specific focus on the development of modeling tools for water and energy planning, Laura refers to a change in methodology which positions individuals in the context of power relations and differentiated structural and contingent everyday challenges. She tells us how gender mainstreaming in long-term resources planning modeling tools could be achieved through a process that deepens our knowledge of both metrics and metaphors; a process able to provide an allencompassing picture of the lived (and unique) realities, and hence situated and embodied experiences and knowledge (Haraway, 1988), of women and men in challenging contexts.

Laura: There is a large constituency of support for gender equality and women's rights from researchers, policy makers and funders. The current challenge is, however, how this constituency can develop the metrics and metaphors that provide evidence so practitioners can support making a difference at the local, regional or national levels. The process of gender mainstreaming towards gender equality therefore needs to be incorporated within a framework that researchers from the various fields can adopt in their analytical work.

Modeling tools for water and energy systems planning have supported resource managers and policy makers at the various governance levels in formulating decisions for a sustainable future. This process is focused on the identification of challenges that decision-makers face, which drives the metrics evaluated in the model, and the type of output analysed when formulating a decision. Assisting water managers in incorporating gender equity aspects in their future long-term planning, ensures that current inequalities are not perpetuated.

The SEI GSE program has developed a guidance document for mainstreaming gender in modelling activities and a training tutorial for an energy and water systems planning tools. However, while having a tutorial for modelling activities opens the door for researchers to evaluate gender aspects, the tutorial by itself is not enough. The process of mainstreaming gender within modelling-based research needs to incorporate the metrics, evidence, and practice from the identification of challenges to the evaluation of outcomes. That way, gender aspects are part of the key metrics to be evaluated in the model, and researchers can effectively evaluate them in the modelling tools. Mainstreaming gender needs to create a process that informs the metrics and the dialogue of policy makers to ensure that change happens. Having a modelling platform and a technical process designed to incorporate gender aspects in resource planning mechanisms facilitates a process towards a gender equal and sustainable future. 
Yet while gender mainstreaming efforts at SEI are well accepted and benefit from active support, it is in projects that it is harder to include. Often funds are not available to support gender inclusion in the type of projects we have. Fortunately, lately there have been some changes. My colleagues and I do as much as we can within project objectives and budget to promote input from women in workshops and trainings. Yet it could be more impactful if the project includes a gender component in the analysis to support the exploration of what are the data, model, metrics that we need to consider to address gender differences in water access, water management, and adapting to water related challenges such as climate change impacts on water resources. It would be also important to have funders supporting aspects related to gender equality and women's empowerment in capacity building activities, workshop developments and decision-making processes.

Lisa: What do you consider as good data that will make the case for integrating gender into the environmental program or project you are jointly working on with other technical colleagues?

Laura: Demographic data or resource demand information disaggregated by gender is something that can help quantitative analysis. But we should not stop there. I think that the main challenge is the opportunity cost women face when they don't have direct access to water and they need to walk for miles. In that case, disaggregated water use data may not be as relevant as the time spent in getting water. In the model, when a water access strategy is implemented, a variable can be created to estimate that time, based on water supply estimates. This is an example of looking at the opportunity cost in having to walk miles to obtain water. Alternatively, an estimation of that time can be evaluated as the trade-off in time dedicated to educating girls and women.

But it is also about working with a different approach. The framing (ontology) around water management, and the key metrics that define satisfactory management, needs a more holistic and distributed approach that can help design new methodologies on water resources research. For example, a case study developed in Bolivia where we disaggregated the demands and were able to capture inequalities that were hidden in the standard models. Another example is a project in Cambodia where SIDA's framework for poverty analysis informed a water resources planning model to address inequalities. By using a different approach, we are working to ensure that sustainable water management happens in tandem with efforts to achieve social equality, economic growth, and poverty reduction.

Marisa added to the discussion. While highlighting the relevance of including more women technical experts, her reflection uncovered the gender politics of gender work.

Marisa: My experience integrating gender has evolved in the last few years. Initially, the development projects I worked on did not mention gender, or when they mentioned it, they did not keep track of the progress 
thoroughout the project to see how gender could be integrated at different stages. Another delicate component of bringing gender into projects occurs when big consulting firms manage development and environmental projects. In those instances, work can be presented as gender sensitive on the front page of the project, yet gender issues remain not addressed internally. Through the gender initiative in SEI I have been able to make time for a focused effort about how to integrate gender into our water resources modelling work. As a result, the relevance of integrating gender into the modelling work and of including women as technical experts in the analysis is established. With these two key components, and with particular strategies to include them, we can now more explicitly include gender considerations into our work.

I found it essential that there is at least one woman in each of the technical teams. The importance of having that woman is that she can embody the importance of gender considerations. This is particularly significant in specific contexts where women are persistently left out of the technical work. In those cases, the gender transformational work needs to go beyond the project itself and address societal unbalances. During the implementation of a current project in Bolivia, for example, one of the women representative of the team has proposed visiting schools. The motivation behind those visits was to make girls understand, at a very early age, that women can aspire to and undertake technical careers, such as engineering. Structural change, and power unbalances, need to be addressed at different levels and girls in schools need to see other women as role models when they are young enough to imagine a future when they can also be in that position.

\section{Some concluding remarks}

Thinking through our experiences, a picture of diversity but also of intersecting paths has emerged. This diversity related to factors ranging from disciplinary backgrounds and the cultures and geographies of work. While earlier it seemed as if a clear distinction between the professional paths and perspectives of the technical scientist and the gender specialist was shaping up, this distinction eventually blurred when SEI colleagues began to share their stories of 'want-to-be' gender professional, of 'becoming' gender experts and/or gender champions and the challenges and dilemmas in their work.

Furthermore, the search for transformative approaches to integrate gender in environmental and natural resources fields was also central to our discussion showing a common struggle despite our different ways of knowing and hence different methodologies of work. But all the more important, being reflexive about our positions - and realising inequalities in our own positionings - has allowed us to get a better sense of the broader, and at the same time deeper, common meaning of our work 'as someone oriented not only to interpret the world but to change it' (Pante, 2014: 82 after Marx, K. 1888 Thesis Eleven in 'Theses on Feuerbach'). 
Connections beyond our field of work per se were also revealed by our considerations on the use of a critical gender lens that enables us to recognise historical and contemporary oppressions, patriarchal limitations in our workplaces and societies we live in, social and personal gender biases. Both in praxis and in theory, the mainstreaming of gender frameworks and gender analysis needs to account for the 'breadth and specificity of oppressions' (Bartlett, 1989: 949) lived by different women and men. The need for intersectionality, as Lisa reminds us, not always privileged by environment and development work, was highlighted here for there is a risk that existing inequalities are ignored and/or exacerbated if multiple, intersecting markers of structural and contingent discrimination are ignored. Those factors are often not captured if tools for gender analysis do not go beyond the use of gender as a variable and lack sufficient consideration of power relations.

Finally, our conversations highlighted how an approach to climate and environmental change and its impacts which sees problems as mainly technical, tends to acknowledge and rely on traditional natural sciences only. Finding its heritage in the developments of the nineteenth century, this approach brought to light the relationship between science/scientific knowledge, economic growth and the expanding market economy. What we hence witnessed was the rise of a 'culture of knowledge' that has taken the scientific rhetoric of 'evidence' into the wider public sphere while depoliticising both knowledge and intervention. Yet accounts of 'changing framings and metrics' around water management for instance, exposed an underlying shared ontology for social justice and its potential to yet again blur disciplinary distinctions and bridge our knowledges.

\section{References}

Abir-Am, P. G., \& Outram, D. (Eds.) (1987). Uneasy Careers and Intimate Lives: Women in Science 1789-1979. The Douglass series on women's lives and the meaning of gender. Brunswick-London: Rutgers University Press.

Arora-Jonsson, S. (2017). Gender and environmental policy. In S. MacGregor (Ed.), Routledge Handbook of Gender and Environment (pp. 289-303). Oxon \& New York: Routledge.

Bartlett, K. T. (1989). Feminist legal methods. Harvard Law Review, 103, 829-888.

Bustelo, M., Ferguson, L., \& Forest, M. (Eds.) (2016). The Politics of Feminist Knowledge Transfer: Gender Training and Gender Expertise. Basingstoke: Palgrave.

Cornwall, A. (2007). Revisiting the gender agenda. IDS Bulletin, 38(2), 69-77.

Denzin, N. K. (1997). Interpretive Ethnography: Ethnographic Practices for the 21st Century. Thousand Oaks, CA: Sage.

Ferguson, L. (2015). 'This is our gender person': The messy business of working as a gender expert in international development. International Feminist Journal of Politics, 17(3), 380-397.

Fricker, M. (2007). Epistemic Injustice: Power and the Ethics of Knowing. Oxford, UK: Oxford University Press.

Haraway, D. (1988). Situated knowledges: The science question in feminism and the privilege of partial perspective. Feminist Studies, 14, 575-599. 
Kunz, R., \& Prügl, E. (2019). Introduction: Gender experts and gender expertise. European Journal of Politics and Gender. Special Issue: gender experts and gender expertise, 10(10), 1-18.

MacGregor, S. (2017). Gender and environment: An introduction. In S. MacGregor (Ed.), Routledge Handbook of Gender and Environment (pp. 1-24). Oxon and New York: Routledge.

Merchant, C. (1980). The Death of Nature: Women, Ecology, and the Scientific Revolution. San Francisco, US: HarperCollins.

Merchant, C. (2006). The scientific revolution and the death of nature. Focus - Isis, 97, 513-533.

Pante, B. L. P. (2014). Female researchers in a masculine space: Managing discomforts and negotiating positionalities. Philippine Sociological Society, 62, 65-88.

Prügl, E. (2013). Gender expertise as feminist strategy. In G. Caglar, E. Prügl \& S. Zwingel (Eds.), Feminist Strategies in International Governance (pp. 57-73). London \& New York, NY: Routledge.

Seager, J. (2017). Rachel Carson was right - then, and now. In S. MacGregor (Ed.), Routledge Handbook of Gender and Environment (pp. 27-42). Oxon and New York: Routledge. 
Taylor \& Francis

Taylor \& Francis Group

http://taylorandfrancis.com 